\title{
Effects of Acupuncture on Quality of Life and Pain in Patients with Venous Ulcers
}

\author{
Maria de Lourdes Guarnieri Barbosa Bueno ${ }^{1}$, Geraldo Magela Salomé2* and Lydia Masako Ferreira ${ }^{3}$ \\ ${ }^{1}$ MS Student Program in Applied Health Sciences, Sapucaí Valley University (UNIVÁS), Brazil \\ ${ }^{2}$ Affiliate Professor, Professional Master's Program in Applied Health Sciences, Sapucaí Valley University UNIVÁS, Brazil \\ ${ }^{3}$ Division of Plastic Surgery, Federal University of São Paulo (UNIFESP), Brazil
}

Received: 阱 August 11, 2018; Published: 眥 August 24, 2018

*Corresponding author: Geraldo Magela Salomé, Av. Francisco de Paula Quintanilha Ribeiro 280, apt.134, Jabaguara CEP- 04330-

020 São Paulo, SP, Brazil

Abstract

Objective: To assess quality of life and pain in patients with venous leg ulcers treated with acupuncture.

Design: A multicenter, prospective, comparative, descriptive, controlled trial was conducted between May 2013 and April 2014.

Settings: Three health care facilities in Brazil

Patients: Eighty consecutive patients with venous leg ulcers were allocated to either the AC group (acupuncture treatment, $n=40$ ) or control group (conservative treatment, $\mathrm{n}=40$ ). Most patients in both groups were women, Caucasians and smokers, with no significant differences between groups. The majority of patients had the ulcer from 6-10 years. Main Outcome Measures: Quality of life and pain were assessed at inclusion and after 3 and 6 weeks of treatment using the Flanagan Quality of Life Scale (FQOLS) and a visual analog scale (VAS), respectively.

Results: After 3 weeks of treatment, VAS pain scores were significantly lower in the AC group compared with controls $(\mathrm{P}=0.028)$, but not after 6 weeks of treatment $(P=0.597)$. A significant decrease in mean VAS pain scores $(P<0.001)$ was found in the AC group at 6 weeks (mean, 0.85$)$ compared with baseline (mean, 6.55). Controls had significantly higher FQOLS scores (mean, 90.05) than patients in the AC group (mean, 73.15) at baseline, but not after 6 weeks of treatment (controls' mean score, 45.76; AC group's mean score, 85.58; P = 0.001).

Conclusion: Patients treated with acupuncture experienced reduction in pain from baseline and better quality of life than controls after 6 weeks of therapy.

Keywords: Acupuncture; Quality of Life; Pain; Varicose Ulcer; Leg Ulcer

Summary

Effects of acupuncture on quality of life and pain were assessed in 80 venous ulcer patients using the Flanagan Quality of Life Scale and a VAS pain scale. Patients treated with acupuncture experienced reduction in pain from baseline and better quality of life than controls after 6 weeks of therapy.

\section{Introduction}

Venous ulcers are a global public health problem that affects the distal third of the legs and correspond to $70-90 \%$ of all lower limb ulcers [1]. Patients with venous leg ulcers experience impaired mobility and pain, which have a negative impact on their quality of life. In addition, the presence of wound exudate and foul odor may lead to changes in the patient's lifestyle and social isolation and interfere with recreation and family activities. These patients often express feelings of frustration, loss of hope and fear related to their treatment because some ulcers may take months to heal [2-4]. Commonly, patients with venous leg ulcers complain of pain, which is associated with the tissue lesion. However, pain perception depends on a number of factors intrinsic to the patients, type of ulceration, and intensity of external stimuli. The skin is richly innervated, having the ability to capture various types of stimuli.

It has numerous highly specialized neurotransmitters known as free nerve endings. When the skin is damaged, cutaneous neurotransmitters and receptors are activated and trigger action potentials, conveying the nociceptive (painful) stimuli to the central nervous system. The presence of infection and necrosis increases wound pain [5]. Health professionals caring for patients with wounds should assess pain regularly, because high pain intensity is associated with increased anxiety symptoms, which may affect treatment adherence and, consequently, the quality of life of this population [5,6]. Acupuncture is among the various 
alternative therapies. In the classical view, the goal of acupuncture is to re-establish the balance of body energies by stimulating points located along lines on the body surface known as meridians. Some mechanisms of action of acupuncture, including analgesia, have been confirmed by Western medicine [7]. Acupuncture is an ancient Chinese practice that has been used in the Western countries and involves the application of thin, flexible needles into specific points distributed in the body for stimulation of peripheral nerves located at the sites of needle insertion.

This process results in alteration of neurotransmitter levels in the central nervous system, with consequent modulation of positive responses to energy imbalances [8]. Quality of life is a polysemous expression and there is still no consensus on the definition of this subjective concept, which involves physical, psychological, social, cultural, and spiritual elements of the human condition. According to the World Health Organization (WHO-QOL group), quality of life is defined as 'the individuals' perception of their position in life in the context of the culture and value systems in which they live and in relation to their goals, expectations, standards and concerns $[9,10]$ Studies assessing quality of life and pain in patients receiving acupuncture treatment have emerged in the scenario of research directed toward health services and clinical practice as important sources of information for the determination of the therapeutic benefit of this technique and its possible use as a treatment modality. Considering that pain is intrinsically associated with quality of life in patients with venous leg ulcers, the aim of this study was to assess quality of life and pain in patients with venous ulcers treated with acupuncture.

\section{Methods}

This multicenter, prospective, comparative, descriptive, controlled study was conducted between May 2013 and April 2014. The study was approved by the Institutional Research Ethics Committee (approval number 366968) and performed in accordance with the ethical standards of the 1964 Declaration of Helsinki and its subsequent amendments. Written informed consent was obtained from all patients prior to their inclusion in the study, and anonymity was assured. Eighty consecutive patients with venous leg ulcers were recruited from a primary health care unit, a health center and an outpatient wound care clinic in Brazil. Eligibility criteria included patients $\geq 18$ years of age of both genders, diagnosed with venous leg ulcer, with ankle-brachial index (ABI) ranging from 0.8-1.0 and a single ulcer. Exclusion criteria were skin lesions other than venous leg ulcers (e.g., mixed ulcers, diabetic foot ulcers, and pressure ulcers) and $\mathrm{ABI}<0.8$ for exclusion of peripheral arterial disease (PAD).

Patients who were unable to complete the questionnaires due to cognitive deficit, such as those with dementia or mental confusion, were excluded from the study, as well as those who missed an acupuncture session. Eighty patients who met criteria were assigned to either the control group and received conservative treatment $(n=40)$ or AC group and received acupuncture therapy, consisting of 6 weekly sessions $(n=40)$. Patients in the AC group were instructed not to take analgesics. All participants were assessed for quality of life and pain at inclusion and after 3 and 6 weeks of treatment using the Flanagan Quality of Life Scale (FQOLS) and a visual analog scale (VAS), respectively.

\section{The Acupuncture Treatment}

Patients in the AC group were placed in an appropriate and quiet environment. The tongue and pulse were inspected and medical history was taken to identify energy imbalances based on signs and symptoms. The same protocol and acupuncture points were used in all patients to prevent bias. Acupuncture points were stimulated to tonify the spleen, dissipate Qi (energy) and Xue (blood) from the liver, nourish the kidneys and liver, clear the mind, decrease stress, anxiety and depression, and act in emotional disturbances. Sterilized disposable stainless steel acupuncture needles $0.25 \mathrm{x}$ $30 \mathrm{~mm}$ with a spiral-shaped handle were inserted in the skin in predetermined points, according to the protocol. The needles were inserted at different inclinations using a plastic guide tube.

\section{Assessment Tools}

Three instruments were used for data collection: a questionnaire assessing sociodemographic characteristics of patients and clinical characteristics of the wound, the FQOLS, and a VAS for pain. The FQOLS was developed in the USA, [11] translated into Brazilian Portuguese, [12] and tested for reliability, [13,14] showing good to excellent reliability, which contributed to the decision to use this tool in the present study. The FQOLS is composed of 15 items grouped into 5 domains of quality of life: material and physical well-being; relationships with other people; social, community, and civic activities; personal development and fulfillment; and recreation. Items are rated on a 7-point Likert-type scale ranging from "very dissatisfied" [1] to "very satisfied [7], yielding a possible range of [15] to 105, with higher scores indicating better quality of life. It is a self-administered questionnaire; however, older patients with physical limitations (e.g., hand tremor and visual and hearing impairments) and those with a low education level received help in completing the questionnaire from an investigator $[11,14]$ Pain intensity was assessed using a VAS, which was presented to the patient who was asked to rate his pain from 0 (no pain) to 10 (worst possible pain). Pain was then classified as absent (rating 0), mild (rating 1-3), moderate (rating 4-6), and severe (rating 7-10) $[15,16]$.

\section{Statistical Analysis}

Friedman's test was used to evaluate differences in VAS pain scores, FQOLS scores, and period effects between groups. If differences were found, individual comparisons were made using the Wilcoxon-Mann-Whitney test. Cochran's Q test was performed to compare improvements in pain and quality of life within groups at a time point, and a chi-square test was used to compare differences in improvement of pain and quality of life between groups. All statistical tests were performed at a significance level $\alpha$ of 0.05 ( $\mathrm{p}<0.05)$. Results Most patients in both groups were women (AC group, 70\%; controls, 65\%), Caucasians (AC group, 82.5\%; controls, 70\%), smokers (AC group and controls, 72.5\%), illiterate or had incomplete primary education (AC group, 72.5\%; controls, 
75\%), with no significant differences between groups (Table 1). difference in presence of exudate (AC group, 55\%; controls, 80\%; P Also, the majority of patients had the ulcer from 6-10 years (AC $=0.017$ ), as shown in Table 2 . group, 62.5\%; controls, $77.5 \%$ ), with a significant between-group

Table 1: Sociodemographic characteristics of patients with venous leg ulcer.

\begin{tabular}{|c|c|c|c|c|c|c|c|}
\hline \multirow[t]{3}{*}{ Variables } & \multicolumn{6}{|c|}{ Groups } & \multirow[t]{3}{*}{$P$-value } \\
\hline & \multicolumn{2}{|c|}{ Control } & \multicolumn{2}{|c|}{ Acupuncture } & \multicolumn{2}{|c|}{ Total } & \\
\hline & $\mathbf{n}$ & $\%$ & $\mathbf{n}$ & $\%$ & $\mathbf{N}$ & $\%$ & \\
\hline \multicolumn{8}{|l|}{ Ethnicity } \\
\hline Caucasians & 28 & 70.0 & 33 & 82.5 & 61 & 76.3 & \multirow{2}{*}{0.293} \\
\hline Mixed race & 12 & 30.0 & 7 & 17.5 & 19 & 23.8 & \\
\hline Total & 40 & 100 & 40 & 100 & 80 & 100 & \\
\hline \multicolumn{8}{|l|}{ Age (years) } \\
\hline$<50$ & 4 & 10.0 & 8 & 20.0 & 12 & 15.0 & \multirow{5}{*}{0.378} \\
\hline $50-59$ & 10 & 25.0 & 8 & 20.0 & 18 & 22.5 & \\
\hline $60-69$ & 20 & 50.0 & 15 & 37.5 & 35 & 43.8 & \\
\hline $70-79$ & 6 & 15.0 & 7 & 17.5 & 13 & 16.3 & \\
\hline$\geq 80$ & 0 & 0 & 2 & 5.0 & 2 & 2.5 & \\
\hline Total & 40 & 100 & 40 & 100 & 80 & 100 & \\
\hline \multicolumn{8}{|l|}{ Gender } \\
\hline Women & 26 & 65.0 & 28 & 70.0 & 54 & 67.5 & \multirow{2}{*}{0.812} \\
\hline Men & 14 & 35.0 & 12 & 30.0 & 26 & 32.5 & \\
\hline Total & 40 & 100 & 40 & 100 & 80 & 100 & \\
\hline \multicolumn{8}{|l|}{ Smoker } \\
\hline No & 11 & 27.5 & 11 & 27.5 & 22 & 27.5 & \multirow{2}{*}{1.00} \\
\hline Yes & 29 & 72.5 & 29 & 72.5 & 58 & 72.5 & \\
\hline Total & 40 & 100 & 40 & 100 & 80 & 100 & \\
\hline \multicolumn{8}{|l|}{ Education level } \\
\hline Illiterate & 18 & 45.0 & 0 & 0 & 18 & 22.5 & \multirow{7}{*}{0.939} \\
\hline Functionally illiterate & 9 & 22.5 & 9 & 22.5 & 18 & 22.5 & \\
\hline Incomplete primary education & 3 & 7.5 & 20 & 50.0 & 23 & 28.7 & \\
\hline Complete primary education & 2 & 5.0 & 4 & 10.0 & 6 & 7.5 & \\
\hline $\begin{array}{l}\text { Incomplete high school } \\
\text { education }\end{array}$ & 3 & 7.5 & 2 & 5.0 & 5 & 6.3 & \\
\hline Complete high school education & 5 & 12.5 & 4 & 10.0 & 9 & 11.3 & \\
\hline College degree & 0 & 0 & 1 & 2.5 & 1 & 1.3 & \\
\hline Total & 40 & 100 & 40 & 100 & 80 & 100 & \\
\hline
\end{tabular}

*Chi-square test for independence $(\mathrm{P}<0.05)$ 
Table 2: Characteristics of the venous leg ulcers.

\begin{tabular}{|c|c|c|c|c|c|c|c|}
\hline \multirow[t]{3}{*}{ Variables } & \multicolumn{6}{|c|}{ Groups } & \multirow{3}{*}{$P$-value } \\
\hline & \multicolumn{2}{|c|}{ Acupuncture } & \multicolumn{2}{|c|}{ Control } & \multicolumn{2}{|c|}{ Total } & \\
\hline & $\mathbf{n}$ & $\%$ & $\mathbf{n}$ & $\%$ & $\mathbf{n}$ & $\%$ & \\
\hline \multicolumn{8}{|c|}{ Ulcer duration (years) } \\
\hline$<1$ & 4 & 10.0 & 2 & 5.0 & 6 & 7.5 & \multirow{4}{*}{0.490} \\
\hline $1-5$ & 6 & 15.0 & 3 & 7.5 & 9 & 18.7 & \\
\hline $6-10$ & 25 & 62.5 & 31 & 77.5 & 56 & 70.0 & \\
\hline$\geq 11$ & 5 & 12.5 & 4 & 10.0 & 9 & 11.3 & \\
\hline Total & 40 & 100 & 40 & 100 & 80 & 100 & \\
\hline \multicolumn{8}{|l|}{ Exudate } \\
\hline No & 18 & 45.0 & 8 & 20.0 & 26 & 32.5 & \multirow{2}{*}{$* 0.017$} \\
\hline Yes & 22 & 55.0 & 32 & 80.0 & 50 & 67.5 & \\
\hline Total & 40 & 100 & 40 & 100 & 80 & 100 & \\
\hline \multicolumn{8}{|l|}{ Odor } \\
\hline No & 17 & 42.5 & 9 & 22.5 & 26 & 32.5 & \multirow{2}{*}{0.56} \\
\hline Yes & 23 & 57.5 & 31 & 77.5 & 54 & 67.5 & \\
\hline Total & 40 & 100 & 40 & 100 & 80 & 100 & \\
\hline
\end{tabular}

*Chi-square test for independence $(\mathrm{P}<0.05)$

Table 3: Clinical characteristics of patients with venous leg ulcers.

\begin{tabular}{|c|c|c|c|c|c|c|c|c|}
\hline \multirow{3}{*}{\multicolumn{2}{|c|}{ Variables }} & \multicolumn{6}{|c|}{ Groups } & \multirow{3}{*}{$P$-value } \\
\hline & & \multicolumn{2}{|c|}{ Acupuncture } & \multicolumn{2}{|c|}{ Control } & \multicolumn{2}{|c|}{ Total } & \\
\hline & & $\mathbf{n}$ & $\%$ & n & $\%$ & $\mathbf{n}$ & $\%$ & \\
\hline \multirow[t]{3}{*}{ Diabetes } & No & 32 & 80.0 & 37 & 92.5 & 69 & 86.3 & 0.193 \\
\hline & Yes & 8 & 20.0 & 3 & 7.5 & 11 & 13.8 & \\
\hline & Total & 40 & 100 & 40 & 100 & 80 & 100 & \\
\hline \multirow[t]{3}{*}{ Hypertension } & No & 26 & 65.0 & 20 & 50.0 & 46 & 57.5 & 0.258 \\
\hline & Yes & 14 & 35.0 & 20 & 50.0 & 34 & 42.5 & \\
\hline & Total & 40 & 100 & 40 & 100 & 80 & 100 & \\
\hline \multirow[t]{3}{*}{ Heart disease } & No & 30 & 75.0 & 35 & 87.5 & 65 & 81.3 & 0.252 \\
\hline & Yes & 10 & 25.0 & 5 & 12.5 & 15 & 18.8 & \\
\hline & Total & 40 & 100 & 40 & 100 & 80 & 100 & \\
\hline
\end{tabular}

*Chi-square test for independence $(\mathrm{P}<0.05)$

Table 4: Mean VAS pain scores for the acupuncture and control groups at different time intervals.

\begin{tabular}{|c|c|c|c|c|c|c|c|c|c|}
\hline \multirow{3}{*}{ Time points } & \multicolumn{8}{|c|}{ VAS pain scores } & \multirow{3}{*}{$P$-value } \\
\hline & \multicolumn{4}{|c|}{ AC group $(n=40)$} & \multicolumn{4}{|c|}{ Control Group $(n=40)$} & \\
\hline & Mean & SD & Min. & Max. & Mean & SD & Min. & Max. & \\
\hline Baseline & 6.55 & 2.062 & 3 & 10 & 7.75 & 1.780 & 4 & 10 & $* 0.007$ \\
\hline at 3 weeks & 3.68 & 1.803 & 1 & 7 & 4.50 & 1.468 & 2 & 7 & $* 0.028$ \\
\hline at 6 weeks & 0.85 & 0.904 & 0 & 3 & 0.70 & 0.723 & 0 & 2 & 0.597 \\
\hline
\end{tabular}

SD, standard deviation; Min., minimum value; Max., maximum value.

*Friedman's test, Mann-Whitney test and Cochran's Q test $(\mathrm{P}<0.05)$.

There were no significant differences in presence of diabetes, group's mean VAS score, 6.55; $\mathrm{P}<0.001$ ). No significant difference hypertension and heart disease between groups Table 3. Within- in mean VAS pain score was found between groups after 6 weeks of group comparisons showed a significant decrease in mean VAS pain treatment $(\mathrm{P}=0.597)$, as seen in Table 4 . There was no significant scores for both the control and AC groups after 6 weeks of treatment difference in levels of pain at baseline $(\mathrm{P}=0.105)$ between groups (controls' mean VAS score, 0.70; AC group's mean VAS score, 0.85) (Table 5). Patients in the AC group reported significantly lower compared with baseline (controls' mean VAS score, 7.75; AC levels of pain than controls after 3 weeks of treatment $(\mathrm{P}=0.029)$. 
After 6 weeks of treatment, no significant difference was observed in levels of pain between groups ( $\mathrm{P}=0.094)$, but all patients in the AC group reported absent or mild pain, while few patients in the control group reported moderate $(n=3 ; 7.5 \%)$ or intense pain $(n=$ $2 ; 5 \%$ ) at the end of the study (Table 5).

Table 5: Distribution of patients according to the different levels of pain (VAS pain scores) for both groups at different time intervals.

\begin{tabular}{|c|c|c|c|c|c|c|c|c|}
\hline \multirow{3}{*}{ Treatment time points } & \multirow[t]{3}{*}{ VAS pain scores } & Groups & & & & & & \multirow{3}{*}{$P$-value } \\
\hline & & \multicolumn{2}{|c|}{ AC group } & \multicolumn{2}{|c|}{ Control group } & \multicolumn{2}{|c|}{ Total } & \\
\hline & & n & $\%$ & $\mathbf{n}$ & $\%$ & $\mathbf{n}$ & $\%$ & \\
\hline \multirow{5}{*}{ Baseline } & 0 (absence) & 0 & 0 & 0 & 0 & 0 & .0 & \multirow{4}{*}{0.105} \\
\hline & $1-3$ (mild) & 2 & 5.0 & 0 & 10.0 & 2 & 2.5 & \\
\hline & 4-6 (moderate) & 20 & 50.0 & 14 & 25.0 & 33 & 41.3 & \\
\hline & 7-10 (intense) & 18 & 45.0 & 26 & 65.0 & 45 & 56.3 & \\
\hline & Total & 40 & 100 & 40 & 100 & 80 & 100 & \\
\hline \multirow{5}{*}{3 weeks } & 0 (absence) & 0 & .0 & 0 & .0 & 0 & .0 & \multirow{4}{*}{$* 0.029$} \\
\hline & $1-3$ (mild) & 22 & 55.0 & 10 & 25.0 & 32 & 40.0 & \\
\hline & 4-6 (moderate) & 15 & 37.5 & 26 & 65.0 & 41 & 51.2 & \\
\hline & 7-10 (intense) & 3 & 7.5 & 4 & 10.0 & 7 & 8.8 & \\
\hline & Total & 40 & 100 & 40 & 100 & 80 & 100 & \\
\hline \multirow{5}{*}{6 weeks } & 0 (absence) & 16 & 40.0 & 10 & 25.0 & 26 & 32.5 & \multirow{4}{*}{0.094} \\
\hline & 1-3 (mild) & 24 & 60.0 & 25 & 62.5 & 49 & 61.2 & \\
\hline & 4-6 (moderate) & 0 & 0 & 3 & 7.5 & 3 & 3.8 & \\
\hline & 7-10 (intense) & 0 & 0 & 2 & 5.0 & 2 & 2.5 & \\
\hline & Total & 40 & 100 & 40 & 100 & 80 & 100 & \\
\hline
\end{tabular}

${ }^{*}$ Chi-square test for independence $(\mathrm{P}<0.05)$.

At baseline, controls had significantly higher $(\mathrm{P}=0.001) \mathrm{FQOLS}$ scores (mean score, 90.05), corresponding to better quality of life than patients in the AC group (mean score, 73.15), but not after 6 weeks of treatment (controls' mean score, 45.76; AC group's mean score, 85.58; $\mathrm{P}=0.001$ ), as shown in Table 6. When compared with baseline, there was a significant decrease in mean FQOLS scores in the control group (mean baseline score, 90.05; mean 6-week score, 45.76) and a significant increase in FQOL scores in the AC group (mean baseline score, 73.15; mean 6-week score, 85.58) at the end of the study.

Table 6: Mean scores on the Flanagan Quality of Life Scale (FQOLS) for the acupuncture and control groups at different time intervals.

\begin{tabular}{|c|c|c|c|c|c|c|c|c|c|}
\hline \multirow{3}{*}{ Time points } & \multicolumn{8}{|c|}{ FQOLS scores } & \multirow{3}{*}{ P-Value } \\
\hline & \multicolumn{4}{|c|}{ AC group } & \multicolumn{4}{|c|}{ Control group } & \\
\hline & Mean & SD & Min. & Max. & Mean & SD & Min. & Max. & \\
\hline Baseline & 73.15 & 10.717 & 53 & 96 & 90.05 & 14.490 & 53 & 110 & ${ }^{*} 0.001$ \\
\hline 3 weeks & 79.50 & 8.659 & 61 & 96 & 69.60 & 12.788 & 45 & 98 & $* 0.001$ \\
\hline 6 weeks & 85.58 & 9.647 & 68 & 103 & 45.76 & 16.449 & 21 & 89 & ${ }^{*} 0.001$ \\
\hline
\end{tabular}

$\mathrm{SD}$, standard deviation; Min, minimum value; Max, maximum value.

*Friedman's test, Mann-Whitney test and Cochran's Q test $(\mathrm{P}<0.05)$.

\section{Discussion}

The incidence of venous leg ulcers is higher among women and increases with age, especially after age 60 [17-21] Most participants in this study were women, were aged $\geq 61$ years, had incomplete primary education, and were smokers, which is in agreement with the profile of patients in previous studies on venous leg ulcers [19] [22-25] Knowing the education level of patients helps health professionals to provide adequate information to patients about venous leg ulcers, the treatment, and how to prevent complications. Due to the high percentage of patients with low education, the use of appropriate interventions is essential for the treatment of this population. Interventions should be designed to assess patient's knowledge on the condition, provide educational information, and encourage self-care and changes in life style that could improve their quality of life $[26,27]$ Education level may affect self-care, especially in patients with chronic diseases who may need to follow complex drug regimens, diets, and instructions for wound and dressing care.

High educational levels are associated with more job opportunities, better income, and better adherence to treatment, which is usually carried out by specialists [28-30] Smoking causes oxidative damage to tissues, reduces immune responses, increases susceptibility to infection, and inhibits collagen synthesis, interfering with the healing process. Smoking also decreases 
the concentration of functional hemoglobin in the blood, causes pulmonary dysfunction, and impairs oxygen delivery to tissues. Nicotine causes vasoconstriction, which increases the risk of ischemia and development of venous ulcers [31-35]. Treatments for venous leg ulcers commonly involve the continuous wearing of compression stockings or bandages and other devices, which lack aesthetic appeal. Other problems faced by these patients are the presence of exudate and smell of the ulcer, which discourage social interaction, isolating the individuals from friends and family, as many fear prejudices. These factors may lead to low self-esteem and changes in self-concept and quality of life [36-41].

The majority of the participants in this study had ulcers associated with exudate and foul odor and was living with the wound between 6 and 10 years. These factors may have affected the quality of life of these patients because they are often associated with pain, anxiety and depression [36,37,40,41] Acupuncture, regarded as an important part of the Chinese cultural heritage, is based on the Taoist philosophy in which the universe and the human being are in harmony with nature as a whole. This concept involves three basic pillars: The Yin and Yang concept, the five elements (earth, water, air, fire, and metal) and the Zang-fu organs. 39 of the 80 patients with venous leg ulcers in this study, 40 of them received acupuncture administered in 6 weekly sessions and 40 received conventional treatment with analgesics and other drug therapy. No significant difference in levels of pain was found between groups at baseline. However, patients treated with acupuncture reported significantly lower levels of pain than controls after 3 weeks of treatment.

After 6 weeks of treatment, no significant difference was observed in levels of pain between groups, but all patients in the AC group reported absent or mild pain, while few patients in the control group still reported moderate or intense pain. Patients in both groups (acupuncture and conventional treatment) had a significant improvement in pain from baseline to the end of the study. It is important to highlight that patients in the acupuncture group received no medication and were treated solely with acupuncture. In physiological terms, acupuncture is a neuromodulation technique, whose targets include nervous branches and superficial and deep sensory nerve endings, with the purpose of producing functional changes in this neural network [42] A previous study has evaluated the analgesic effect of acupuncture using functional magnetic resonance imaging (fMRI) and proposed a hypothalamuspituitary-adrenal axis model.43 Its results suggest that acupuncture signals activate cortical centers and stimulate the release of anti-inflammatory and analgesic substances through humoral and neural mechanisms, promoting pain relief and consequent improvement in quality of life.

A significant increase in FQOLS scores from baseline to the end of the treatment period was observed in the acupuncture group, corresponding to an improvement in the quality of life of these patients. Patients treated with acupuncture also reported significantly better quality of life than did controls after 6 weeks of treatment. Enhanced quality of life was possibly directly related to reduction in pain. However, patients in the control group reported a significant decrease in FQOLS scores from baseline after 6 weeks of treatment, reflecting a reduction in their quality of life. Acupuncture was efficient for pain relief in patients with venous leg ulcers. The identification of afferent and efferent connections, brain structures, and various neurotransmitters associated with the analgesic effect of acupuncture has been evidenced in the literature $[39,42]$ Allopathic therapies are associated with unwanted side effects. Acupuncture is an efficient alternative therapy for pain relief, whose mechanisms of release of endogenous agents are not associated with deleterious effects such as those of psychoactive drugs.

$[39,42]$ The use of medications has recently become abusive, leading to important side effects, intoxications, drug tolerance, and high treatment costs. On the other hand, acupuncture can adjust the balance of the organism, improve blood circulation, and increase body resistance. This reduces to a minimum the need for drugs and increases therapeutic efficacy. The limitations of this study include the lack of follow-up of the healing process and lack of a randomized design.

\section{Conclusion}

The results indicated that acupuncture may be used in the care of patients with venous leg ulcers. Patients treated with acupuncture reported reduction in pain from baseline and better quality of life than did patients treated with conventional therapy. This study provides relevant information for further investigations on the use of acupuncture in the treatment of venous leg ulcers in the clinical practice. This information may also stimulate patients to seek alternative treatments that have been shown to be effective.

\section{References}

1. Castilho DP, Sagues CR, Urrea RC, Bardisa MJ, López SA (2004) Sural flap in chronic venous leg ulcer. Rev Chil Cir 56: 475-480.

2. L de Lima E, Salomé GM, de Brito Rocha MJ, Ferreira LM (2013) The impact of compression therapy with Unna's boot on the functional status of VLU patients. J Wound Care 22(10): 558-561.

3. Salomé GM, Ferreira LM (2012) Quality of life in patients with venous ulcers treated with Unna's boot compressive therapy. Rev Bras Cir Plast 27(3): 466-471.

4. Salomé GM, Pellegrino DMS, Blanes L, Ferreira LM (2011) Self-esteem in patients with diabetes mellitus and foot ulcers. J Tissue Viability 20(3): 100-106.

5. Alvarado LC, Silva FP, Fogaça V, Beluomini RDG, Dantas SRPE (2011) Pain in outpatients with chronic venous ulcer. Rev Estima 9: 14-23.

6. de Almeida AS, Salomé GM, Dutra RA, Ferreira LM (2014) Feelings of powerlessness in individuals with either venous or diabetic foot ulcers. J Tissue Viability 23(3): 109-114.

7. Wang SM, Kain ZN, White P (2008) Acupuncture analgesia: I The scientific basis. Anesth Analg 106(2): 602-610.

8. Kurebayashi LF, de Freitas GF, Oguisso T (2009) Nurses' perception about diseases that are treated by acupuncture. Rev Esc Enferm USP 43(4): 930-936.

9. Ferrans CE, Powers MJ (1992) Psychometric assessment of the quality of life index. Res Nurs Health 15(1): 29-38.

10. Yamada BFA, Santos VLCG (2005) Quality of life of individuals with chronic venous ulcers. Wounds 17(7):178-89.

11. Flanagan JC (1982) Measurement of quality of life: current state of the art. Arch Phys Med Rehabil 63(2): 56-59. 
12. Hashimoto H, Guedes SL, Pereira VC, O Ostomizado ea, Vida Proposta, et al. (1996) The Ostomist and Quality of Life: Approach Based on the Dimensions of Quality of Life Proposed by Flanagan (Monograph) Escola de Enfermagem/USP.

13. Gonçalves LHT, Nassar SM (1998) Teste de Confiabilidade de EQV de Flanagan (Reliability Test of the Flanagan QOLS) Florianópolis UFSC.

14. Gonçalves LHT, Dias MM, Liz TG (1999) Qualidade de vida de idosos independentes segundo proposta de avaliação de Flanagan (Quality of Life of Independent Elderly According to Flanagans Evaluation Proposal) Mundo Saude 23: 214-220.

15. Barros EJ, Santos SS, Lunardi VL, Lunardi Filho WD (2012) Elderly human being with ostomy and environments of care: reflection on the perspective of complexity. Rev Bras Enferm 65(5): 844-848.

16. Peón AU, Diccini S (2005) Postoperative pain in craniotomy. Rev Lat Am Enfermagem 13(4): 489-495.

17. Pimenta CAM, Teixeira MJ (1996) Adaptation of McGill questionnaire to Portuguese language. Rev Esc Enferm USP 30(3): 473-483.

18. Green J, Jester R (2010) Health-related quality of life and chronic venous leg ulceration: Part 2. Br J Community Nurs 15(3): S4-10.

19. Palfreyman S (2008) Assessing the impact of venous ulceration on quality of life. Nurs Times 104(41): 34-37.

20. Salomé GM, Blanes L, Ferreira LM (2014) The impact of skin grafting on the quality of life and self-esteem of patients with venous leg ulcers. World J Surg 38(1): 233-240.

21. Salomé GM, Ferreira LM (2013) Impact of skin grafting of venous leg ulcers on functional status and pain. World J Surgery 37(6): 1438-1445.

22. Salomé GM, Pellegrino DMS, Vieira TF, Blanes L, Ferreira LM (2012) Sleep quality among patients with venous ulcers: a cross-sectional study in a health care setting in São Paulo, Wounds 24(5): 124-131.

23. Salomé GM, de Almeida SG, Ferreira LM (2014) Evaluation of pain in patients with venous ulcers after skin grafting. J Tissue Viability 23(3): 115-120.

24. Carmo SS, Castro CD, Rios VS, Sarquis MGA (2007) Nursing care to the venous ulcer carrier news. Rev Eletr Enferm 9: 506-517.

25. Bongiovanni CM, Hughes MD, Bomengen RW (2006) Accelerated wound healing: multidisciplinary advances in the care of venous leg ulcers. Angiology 57(2): 139-144.

26. Salomé GM, Pereira VR, Ferreira LM (2013) Spirituality and subjective wellbeing in patients with lower-limb ulceration. J Wound Care 22(5): 230-236.

27. Lourenco L, Blanes L, Salomé GM, Ferreira LM (2014) Quality of life and self-esteem in patients with paraplegia and pressure ulcers: a controlled cross-sectional study. J Wound Care 23(6): 331-337.
28. Frade MAC, Cursi IB, Andrade FF, Samara Casemiro Soares, Wendel S. Ribeiro, et al. (2005) Leg ulcer: an observational study in Juiz de Fora, MG and region. An Bras Dermatol 80(1): 41-46.

29. Bergonse FN, Rivitti EA (2006) Evaluation of arterial circulation using the ankle/brachial blood pressure index in patients with chronic venous ulcers. An Bras Dermatol 81(2): 131-135.

30. Salomé GM, Espósito VH (2008) Vivências de acadêmicos de enfermagem durante o cuidado prestado às pessoas com feridas. Rev Bras Enferm 61(6): 822-827.

31. Thomsen T, Tønnesen H, Møller AM (2009) Effect of preoperative smoking cessation interventions on postoperative complications and smoking cessation. Br J Surg 96(5): 451-61.

32. Kean J (2010) The effects of smoking on the wound healing process. J Wound Care 19(1): 5-8.

33. Lindström D, Wladis A, Pekkari K (2010) The thioredoxin and glutaredoxin systems in smoking cessation and the possible relation to postoperative wound complications. Wounds 22(4): 88-93.

34. Gottrup F, Apelqvist J, Price P (2010) European Wound Management Association Patient Outcome Group. Outcomes in controlled and comparative studies on non-healing wounds: recommendations to improve the quality of evidence in wound management. J Wound Care 19(6): 237-268.

35. da Silva FA, Freitas H, Jorge MS, Moreira TM, de Alcântara MC (2009) Nursing in stomatherapy: clinical care for the patient with varicose ulcer Rev Bras Enferm 62(6): 889-893.

36. Salomé GM, Openheimer DG, de Almeida SA, Bueno MLGB, Dutra RAA, et al. (2013) Feelings of powerlessness in patients with venous leg ulcers. J Wound Care 22(11): 628-634.

37. Pereira MTJ, Salomé GM, Openheimer DG, Espósito VHC, de Almeida SA, et al. (2014) Feelings of powerlessness in patients with diabetic foot ulcers. Wounds 26(6): 132-138.

38. Leake R, Broderick JE (1999) Treatment efficacy of acupuncture: a review of the research literature. Integr Med 1(3): 107-115.

39. Valencia IC, Falabella A, Kirsner RS, Eaglstein WH (2001) Chronic venous insufficiency and venous leg ulceration. J Am Acad Dermatol 44(3): 401421.

40. Salomé GM, Alves SG, Costa VF, Pereira VR, Ferreira LM (2013) Feelings of powerlessness and hope for cure in patients with chronic lower-limb ulcers. J Wound Care 22(6): 300-304.

41. Maciocia G, São Paulo, Roca (2005) Diagnosis in Chinese Medicine: A Comprehensive Guide.

42. Cho ZH, Hwang SC, Wong EK (2006) Neural substrates, experimental evidences and functional hypothesis of acupuncture mechanisms. Acta Neurol Scand 113(6): 370-377.
ISSN: 2574-1241

DOI: 10.26717/BJSTR.2018.08.001641

Geraldo Magela Salomé. Biomed J Sci \& Tech Res

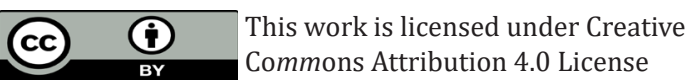

Submission Link: https://biomedres.us/submit-manuscript.php

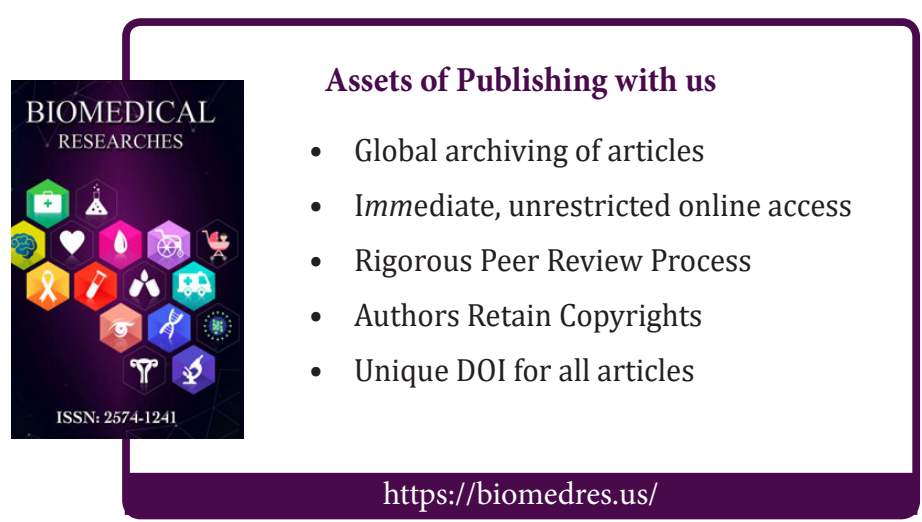

